traditional one. As consumer groups became more inquisitive about how food was being grown, we made a strong attempt to educate those components of society.

Looking toward the future, what is the most important task for the Division and for UC?

HA: I've never been a good crystal ball guy. We sometimes talk in small groups and raise the question, "What is the future of public research as opposed to private?" In pest management, I think the University still has a strong role in looking at systems and developing procedures or programs. We have the ability to look at the total picture when using a pesticide: What's happening to predators? What effect does it have on the soil and on the crop? Recently, the University has gotten involved in larger issues - water issues, effluent issues, land-use issues. We're putting task forces together to come up with programs that legislators can adopt or that will influence decision makers. But I think we will always be involved in the nuts and bolts of agriculture. We should continue to serve as an objective body for interpreting scientific knowledge for growers and consumers.

-Jeannette Warnert

\title{
Jack Dibble
}

\section{Entomologist}

Jack Dibble was one of the UC scientists who built the Kearney Agricultural Center's reputation for first-rank agricultural research. Dibble began his career at UC Berkeley in 1955. Fourteen years later, when the University was establishing the Kearney Ag Center near Parlier, Dibble was reassigned. Though Dibble said he was hesitant at first, "It was the best thing I ever did." During his 36-year career in entomology, Dibble's work has emphasized the screening of pesticides to determine how much and when to make applications for effective pest control. He also studied application techniques and integrated pest management. Dibble retired in 1991, but is still working on several studies at the Kearney Ag Center.

In 1946, when California Agriculture was first published, California was entering a post-World War II era of optimism and prosperity. As you remember that time, what did society expect from the College of Agriculture?

JD: Farmers expected continuous updates on techniques and methods to ensure crops of high quality and yield. They looked to the University, and in particular Cooperative Extension, for transition of information from the campuses to practical use in the field. Consumers expected a wide variety of foods at very affordable prices. That's one of the things that drove investigations of pesticides to control insects and diseases, and synthetic fertilizers to produce larger quantities.

How did those expectations change in subsequent decades and what are they today?

JD: Consumers still expect high quality and high availability of all products, especially here in California. At the same time, they want farmers to reduce the amount of chemicals used, but they don't think the price of food should change. Farmers must be concerned with food safety, increasing labor costs and the costs of more regulations. How much additional cost can you add on to products and still have consumers buy the same quantity they used to? Farmers expect the University to help them meet consumer expectations.

How did you perceive your role as a specialist when you were hired in 1955? How did your job change over the years?

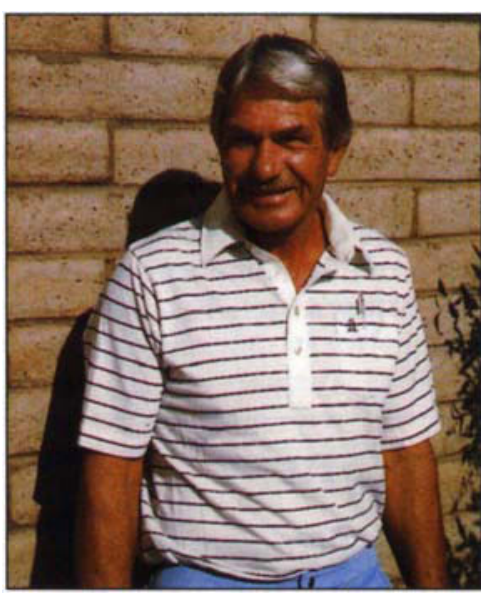

JD: When I was hired, entomology specialists were really not supposed to do any research. Our role was to take research from staff in the department and put it into practice. As years went by, faculty began doing more basic research, and farm advisors starting taking on scientific projects. This required specialists to do original applied research. At the campuses, the teaching load increased and travel funds decreased. Grants started going to specialists and farm advisors to address area problems. The Kearney Ag Center was staffed with entomologists, plant pathologists, nematologists and commodity-oriented specialists from the three campuses: Berkeley, Davis and Riverside. Our focus was research and problem solving, and right in the center of the world's richest ag area, we put together multidisciplinary teams of researchers. People started coming to the Kearney Ag Center for answers. As the staff networked, published and gave talks, it helped build our credibility. It didn't happen overnight; it took 8 to 10 years before this really took off.

What were UC's most significant research and extension contributions' during these years, particularly in your area of expertise or to the industry you served?

JD: I would say the most outstanding accomplishment was our work with low-volume-spray application systems for deciduous tree crops and vines. The low volume system involved using a much smaller quantity of water per acre, and less chemical per acre. About 1960, we started to evaluate all types of sprayers and spray rates 
used in tree crops and vines. We tried to improve the performance of these sprayers by modifying the nozzle system, speed of travel and by making various other adjustments to the units. And then, in more recent years, we became involved in the low-volume concentrate area, which amplified the value of low-volume concentrate sprays to the point that some $85 \%$ of tree crop growers and $90 \%$ of grape growers now use the system.

\section{How have societal changes over the last 50 years influenced the} Division?

JD: The farming community has changed tremendously from small to bigger farms. This has been good for California agriculture and probably the world because we ship products everywhere. The larger growers are very knowledgeable business people. They are as well educated as many farm advisors in varieties, pruning, pest control and other areas. A large grower can produce crops more efficiently and more cheaply. This is a direct reflection on what society demands of agriculture. It's not something agriculture has pushed, but something that society has made "happen."
I've seen another significant change. When I started, there were very few women involved in agriculture. Now we see women in the field, doing research, in administrative positions. There's no difference in expertise. I've worked with three women at Kearney who are outstanding scientists and there are many more in the Division. It's been a good thing for the Division and for agriculture.

Looking toward the future, what is the most important task for the Division and for UC?

JD: I think the Division should continue to maintain contact with farmers and commodity groups by promoting the extension of research and information through the farm advisors. I think we should take a lead role in working with Pest Control Advisors and crop consultants. This way we can actually touch a lot more farmers. Consultants are seeing the farmers every day. If we work with consultants, we are building up our relationship with farmers. The feedback promotes cooperative studies and problem solving.

\section{Pat Snow}

\section{Home Economist}

Pat Snow had just earned her bachelor's degree in home economics at UC Berkeley in 1949 when she applied for the position of 4-H home advisor at the Monterey County Cooperative Extension office. "When I first got the job, I told myself I would leave after 2 years if I didn't like it," Snow said. She retired in 1991 after 42 years. Snow taught clothing construction to women during the early part of her career. She later took on additional home economics and 4-H duties.

California Agriculture was first published in 1946. UC's College of Agriculture (the predecessor to the Division) was on the brink of a great expansion. As you remember that time, what did society expect from the College of Agriculture?

PS: People expected hands-on, personal help. I went out and visited every new leader in the home. These were 4-H project leaders in clothing, food and nutrition, home furnishing and food preservation. People were not so rushed and were eager for our contact.

People wanted the information we had to offer. They kept gardens and froze or canned their harvest. They sewed clothing and wanted instruction on the finer points. Perhaps because they spent so much time in the home, they did a better job of putting it together and caring for it.

How did those expectations change in subsequent decades and what are they today?
PS: As women went to work, you couldn't really meet with them in their homes. I found there was still interest in food preservation, primarily from the foodsafety point of view. Few people had time for sewing. They began doing more crafts. Their interest in home decorating appeared to diminish. Now people call in a decorator, or they just do it themselves. Some are talented and their homes are lovely. Others do what is necessary. They just live there and are working most of the time.

How did you perceive your role as a 4-H advisor when you were hired in 1949? How did your job change over the years?

PS: When I first started, I attended 4-H project meetings during the afternoons and $4-\mathrm{H}$ community club meetings several evenings each week. We offered classes to the home extension women on making coats, men's shirts and wool dresses, to name a few. All of our classes and advice were free.

About the late-1960s, the statewide 4-H office asked us to stop making home visits and attending project meetings. We still went to some night meetings on invitation. The University reduced staff and some rural county populations grew, so our outreach approach 